\title{
A GRIPE SOB A ÓtICA DA HISTÓRIA ECOLÓGICA: UM ESTUdO COMPARATIVO ENTRE AS PANDEMIAS DE 1918 E 2009
}

The Flu From the Perspective of ECological History: a comparative study betWeen the PANDEMics OF 1918 AND 2009

\author{
Charles Klajman* \\ charlesklajman@gmail.com
}

RESUMO: Os autores que escreveram sobre a História Ecológica, relataram o dramático impacto das doenças infecciosas e o papel fundamental no desaparecimento de algumas civilizações dos novos mundos. Através dessa chave, utilizada por William McNeill em Plagues and Peoples (1998), Alfred Crosby em Imperialismo Ecológico (1993) e por Jared Diamond em Armas Germes e Aço (2001), pretendo apresentar um estudo comparativo entre a Gripe Espanhola de 1918 e Gripe Influenza A de 2009, vulgo Suína provocada pelo vírus H1N1, na formatação teórico-metodológica estabelecida por esses autores.

PALAVRAS-ChAVE: Gripe suína, influenza, História Ecológica.

ABSTRACT: The authors who wrote about Ecological History described the dramatic impact and fundamental role of infectious diseases in the disappearance of some civilizations in the New World. By means of this key, used by William McNeill in Plagues and Peoples (1998), by Alfred Cosby in Ecological Imperialism (1993), and more recently by Jared Diamond in Guns, Germs, and Steel (2001), I intend to present a comparative study between the Spanish flu of 1918 and Influenza of 2009, aka Swine caused by the H1N1 virus, in theoreticalmethodological formatting established by these authors..

KEYWORDS: Swine flu, influenza, Ecological History.

\footnotetext{
*Possui graduação em Odontologia pela UNIGRANRIO (1988), Especialização em Radiologia Oral pela Academia Brasileira de Medicina Militar/Hospital Geral de São Paulo, Especialização em Dentística Restauradora pela Odontoclínica Central do Exército/Associação Brasileira de Odontologia Militar, Especialização em História Militar pela Universidade Federal do Estado do Rio de Janeiro/ Instituto de Geografia e História Militar do Brasil e Mestrado em História das Ciências e da Saúde na Casa de Oswaldo Cruz (COC-FIOCRUZ). É Cirurgião-Dentista do Corpo de Saúde do Exército Brasileiro, atualmente chefiando a Divisão de Odontologia da Policlínica Militar da Praia Vermelha, Sócio Titular e Ex-Diretor de Comunicação Social do Instituto de Geografia e História Militar do Brasil (2013/2014).
} 


\section{Introdução}

A interação entre homens e as doenças epidêmicas é tão antiga quanto a história humana e a despeito de toda a evolução tecnológica havida, a população permanece firmemente ligada ao mundo natural.

A História Ecológica ou Ambiental tem como meta:

[...] aprofundar nossa compreensão de como os humanos tem sido afetados pelo seu ambiente natural através do tempo e, contrariamente e talvez de modo mais importante, na visão da insustentável situação global atual, como a ação humana afetou o ambiente e quais foram as conseqüências" (WORSTER, 2002, p.25).

A contabilização dos casos de uma doença epidêmica como a gripe numa determinada região geográfica é complexa, pois, diferentemente da malária e da ancilostomíase que geram "[...] novos casos em qualquer mês de qualquer ano em uma área afetada" (DIAMOND, 2001, p. 202), as moléstias infecciosas respiratórias surgem sem um padrão temporal específico e, portanto, podem ficar muitos anos sem aparecer.

A Influenza tem sido uma grande ameaça ao longo da história da humanidade. Apesar de existirem hoje em dia vacinas disponíveis, todo o ano a doença afeta sazonalmente de $5 \%$ a $15 \%$ da população mundial (RAZURI et al., 2012, p. 318).

No século XX a pandemia de influenza que ficou conhecida como a Gripe Espanhola ${ }^{1}$ ceifou a vida de milhões e serve para ilustrar o impacto que esse tipo de doença infecciosa pode provocar, mesmo nos dias de hoje. Em 2009 a repercussão na mídia das primeiras mortes, a quase catarse por informação e a sensação de completa desinformação a despeito dos enormes esforços das autoridades sanitárias para salvaguardar a vida mundo afora, expôs os efeitos, ainda não completamente esclarecidos de um mundo interconectado ou globalizado.

\footnotetext{
${ }^{1}$ Segundo Phillips e Killingray (2003, p.1), foi indevidamente denominada “espanhola” pela imprensa não européia. Para outros autores, como Trilla et al. (2008, p.668), não há consenso em torno do nome dado à pandemia. Tendo, desde o seu início, sido chamado de gripe espanhola ou Spanish lady, provavelmente por causa da desinformação em torno da notícia sobre sua origem. Uma das hipóteses, deriva da neutralidade espanhola na Primeira Guerra Mundial e a consequente liberdade de imprensa naquele país, maior do que nos países aliados e na Alemanha. Entende o autor que a imprensa norte-americana e européia, provavelmente por razões políticas, não reconheceu ou transmitiu as notícias das baixas pela gripe de forma precisa e oportuna. Hoje, existe o consenso entre virologistas e epidemiologistas de que o vírus da gripe não se originou na Espanha. Entretanto, dificilmente essa pandemia deixará de ser conhecida como gripe espanhola.
} 
Se até o advento da AIDS pensávamos que havíamos triunfado sobre as doenças, os avanços da medicina na época (1918) não tornavam o quadro distinto, pois:

[...] os milagres da medicina eram encarados quase como religião, pelos avanços proporcionados pela teoria microbiana, que, durante os cinqüenta anos que precederam a gripe de 1918, possibilitaram a identificação de diversos patógenos em intervalos quase regulares, e que quase fizeram com que a morte perdesse o seu significado, a espanhola veio zombar do otimismo reinante [...] (KOLATA, 2002, p. 71).

Na primeira década do século XXI, a expectativa de pandemia por influenza estava voltada para a gripe aviária provocada pelo vírus H5N1 e não para a suína. Serviços de saúde em diversas regiões descreviam a situação como uma corrida contra um vírus que se modificava rapidamente. De novembro de 2005 a março de 2006, essa gripe se espalhou de 16 para 37 países em 3 continentes. Não havia na época um suprimento adequado de antivirais nem certeza de sua plena efetividade para esse vírus (OLSON, 2006, p. 46).

A influenza A de $2009^{2}$ percorreu um trajeto clássico com características comuns às doenças respiratórias infecciosas, ao se transmitir de pessoas contaminadas com o vírus para as saudáveis que estivessem ao alcance do patógeno. Se determinada área fosse densamente povoada o número absoluto de casos seria maior. Entretanto, como a evolução foi aguda, a pessoa ou ficou doente e morreu ou se recuperou, e os sobreviventes desenvolveram anticorpos que diminuiram significativamente a chance de uma reinfecção.

Populações isoladas, entretanto, não sofreram a experiência do contágio. Crosby (1976, p.233), corrobora essa idéia ao afirmar que durante a Gripe de 1918 apenas algumas ilhas isoladas do Pacífico não sofreram com a influenza espanhola, muito mais por causa das imensas distâncias de grandes contingentes populacionais do que por efeito de seus anticorpos.

Em 1918 os primeiros casos da Espanhola, surgiram no estado americano do Kansas em fazendas de porcos dessa região. A expectativa no Século XXI, era de que caso eclodisse uma pandemia de influenza, o ponto de partida seria o sul da China, entretanto, o primeiro caso em humanos, aparentemente foi detectado na América do Norte e no México (CHENG,

\footnotetext{
${ }^{2}$ Os vírus influenza são transmitidos facilmente por aerossóis produzidos por pessoas infectadas ao tossir ou espirrar. Existem 3 tipos de vírus influenza: A, B e C. O vírus influenza C causa apenas infecções respiratórias brandas, não possui impacto na saúde pública e não está relacionado com epidemias. O vírus influenza A e B são responsáveis por epidemias sazonais, sendo o vírus influenza A responsável pelas grandes pandemias. Retirado de: http://portalsaude.saude.gov.br/index.php/o-ministerio/principal/secretarias/svs/influenza. Acesso em 16 de maio de 2015.
} 
2012, p. 223). Mais especificamente, parecem ter surgido no estado de Vera Cruz no México, nas Granjas Carroll, subsidiária da Smithfield Foods, a maior produtora de carne de porco do mundo. Tanto em 1918 como em 2009, suinocultores negaram qualquer ligação entre a doença nos porcos e em pessoas (PHILPOTT, 2009).

\section{0 anos de pandemias de gripe}

Alfred Crosby viu paralelos entre a Gripe Espanhola de 1918-19 e a gripe deste século. Segundo ele, as duas se originaram em porcos e foram causadas pelo mesmo vírus influenza, o tipo A (H1N1) ${ }^{3}$. A primeira onda da Espanhola, entre março e junho foi branda. A segunda, que começou no fim de agosto e durou até novembro de 1918, foi letal. Segundo ele, a expectativa em 2009, era de que esse vírus não sofresse mutações e se tornasse mais letal, antes de começar a segunda onda da pandemia, em agosto. Advertia que deveria acontecer não apenas uma segunda onda, como talvez uma terceira (MOON, 2009).

Apesar de similaridades, houve diferenças, principalmente na quantificação de casos. O vírus do século XXI atacou de forma diferente ao da gripe normal, afetando os jovens, os muito obesos e os adultos aparentemente saudáveis, agredindo com força os pulmões. Os mais velhos pareceram ter uma imunidade extra ao novo vírus H1N1, primo distante do H1N1 que causou a pandemia de 1918-19, quando morreram mais de 20 milhões de pessoas ${ }^{4}$, número superior aos mortos na guerra de $1914-1918^{5}$. Essa gripe matou cerca de $2 \%$ da população mundial, pois além de coincidir com um período de guerra, no qual as pessoas estavam debilitadas, os recursos eram escassos e não existiam tratamentos específicos como os antivirais de hoje (MOON, 2009).

No final do século XX, numa expectativa de como e onde fosse se apresentar, a virose provocada pela influenza A continuava a emergir das reservas de aves aquáticas, acarretando pandemias, provavelmente causadas por trocas periódicas nos genes dos vírus influenza entre essas aves e outras espécies aumentando o risco de doenças com o caráter de pandemias em humanos, pequenos animais e pássaros. Haveria a hipótese de que os porcos fossem os hospedeiros intermediários e que a China fosse o epicentro para a evolução humana dessa pandemia. A transmissão da gripe das aves para os porcos na Europa

\footnotetext{
${ }^{3}$ De acordo com Bryan (2014) a "gripe suína" de 2009 foi de fato causada por um vírus recombinante triplo A (H1N1) que continha material genético de aves , suínos e vírus influenza humanos.

${ }^{4}$ Os números de mortos pela pandemia de gripe divergem nas fontes estudadas e referenciadas neste estudo. São encontradas referências que variam de 15 a 50 milhões de mortes causadas pela doença.

${ }^{5}$ Retirado de: http://www.archives.gov/press/press-releases/2009/nr09-77.html. Acesso em 19 de julho de 2015.
} 
em 1979, e a descoberta de genes de vírus humanos recombinados em suínos levou os autores, a questionarem quando uma nova pandemia ocorreria no velho continente (WEBSTER e KAWOKA, 1994 p.103).

No estudo da transmissibilidade de patógenos entre animais e homens, estudos sugeriram elos interligando-a aos germes pelo quantitivo enorme dessas verdadeiras reservas, exemplificando com uma estimativa de mais de 161 milhões de ovelhas na Austrália para uma população humana de pouco mais de 17 milhões na época de seu estudo (DIAMOND, 2001, p. 196). Para nos ajudar a entender essa chave, McNeill enfatiza que os animais domésticos dos ameríndios, por ocasião da chegada de Colombo, não carregavam uma plêiade de infecções que pudesse transferir o seu parasitismo para os humanos, apesar de existir uma densidade populacional que permitisse o contágio. Isso é o que deve ter ocorrido no Velho Mundo, onde manadas de gado e cavalo, dispersos pelas estepes a florestas da Eurásia, eram suficientemente numerosas e tinham um contato próximo o suficiente um com o outro num estado selvagem que permitia sustentar infecções que eram transmitidas de animal para animal, sem nenhum tipo de hospedeiro intermediário. Por comparação, as Ihamas e alpacas que viviam nas alturas dos Andes, eram poucas e em grupos dispersos, e desta forma, não podiam sustentar tais infecções. Com exceção do Porquinho da Índia, as espécies domesticadas pelos ameríndios não foram capazes de suportar as cadeias de infecção transmitidas pelas mais diversas características das doenças civilizadas. Então não é difícil imaginar que uma vez estabelecido o contato, as populações nativas do México e Peru, tornaram-se as vitimas em escala massiva, das doenças comuns na Europa e África (MCNEILL, 1998, p. 209-211).

No espectro microbiológico, a estratégia dos micróbios da gripe para a sua propagação, consistiria em induzir a vítima a tossir ou espirrar, lançando uma nuvem dos mesmos em direção aos possíveis novos hospedeiros. E aí surgiria uma pergunta: diante da perspectiva do germe, por que este desenvolveria uma estratégia aparentemente autodestrutiva, matando o seu hospedeiro? Para o germe, poderia se deduzir que enquanto o paciente estiver vivo, contaminará mais vítimas em potencial, mesmo com a morte do primeiro hospedeiro. Para que o vírus sobreviva, seu hospedeiro também terá de sobreviver, ou seja, é evolutivamente interessante para ele causar menos prejuízo ao infectado. E uma maneira de conseguir essa atenuação é passar diversas vezes de um organismo para outro (DIAMOND, 2001, p. 197-199).

Além da gripe espanhola de 1918-19, epidemias regionais ocorreram nas décadas seguintes. Entretanto, outras pandemias de influenza sucederam antes que sobreviesse a crise de 2009. A Gripe Asiática, de 1957/1958, também causada pela Influenza, desta feita através do H2N2, teve início na China, alastrou-se por diversos países da Ásia, Europa, África, 
Caribe e América do Norte. Segundo Kilbourne (2006, p.10), foi a primeira vez que a rápida disseminação global de um vírus de gripe moderno esteve disponível e permitiu investigação laboratorial. Com exceção de pessoas maiores de 70 anos de idade, o público foi confrontado por um vírus com o qual não tinha tido nenhuma experiência, e que se mostrou letal sozinho, mesmo sem invasores bacterianos adicionais. A Gripe de Hong Kong (1968-69), causada pelo virus H3N2 começou na China espalhou-se por Hong Kong, propagando-se por outros países da Ásia, África, Europa e Estados Unidos. Segundo Chan (2007) a pandemia de 1957 provocou 2 milhões de vítimas fatais e a de 1968, mais de 1 milhão. Em 1997, houve a primeira aparição da Gripe Aviária, detectada em 3 fazendas de Hong Kong, provocada pelo virus Influenza A (H5N1) que infectou 18 habitantes daquele local, todos hospitalizados, com 6 mortos (BRIDGES et al., 2002, p. 1010-1015). O sacrificio de milhões de aves nessa ocasião ajudou a reduzir o risco, mas não foi suficiente para erradicar a ameaça deste vírus em particular (HERRING e LOCKERBIE, 2010, p. 180). A epidemia de SARS (Síndrome Respiratória Aguda Severa) ou pneumonia asiática, foi provocada por outro tipo de vírus, o corona-vírus, que infectou mais de 8 mil pessoas e matou cerca de 700 em 29 países. Surgiu em novembro de 2002, apesar do só ter sido divulgada pela Organização Mundial de Saúde (OMS) no final de fevereiro de 2003. No dia 18 de maio de 2004, a OMS comunicou que o último caso de SARS havia sido isolado há mais de 3 semanas declarando que a cadeia de transmissão de humano para humano parecia ter sido interrompida (WORLD HEALTH ORGANIZATION, 2004).

Considerada uma infecção altamente transmissível, a influenza expõe as conexões globais e a despeito dos intensos estudos sobre o vírus e métodos de proteção da população, este passou em 2009, do ponto de ser uma ameaça, para uma pandemia.

Até mesmo as nossas defesas imunológicas são enganadas pelas gripes que assolam sazonalmente as diferentes populações do planeta.

A constante evolução ou reciclagem de novas variedades de gripe, com antígenos diferentes, explica por que o fato de termos contraído uma gripe dois anos atrás não nos deixa protegidos contra a variedade diferente que apareceu este ano (DIAMOND, 2001, p.200-201).

A taxa de contaminação por doenças infecciosas transmitidas pelo ar sempre é muito alta. Por isso é que todo ano uma nova vacina contra gripe é fabricada. Mas no caso da Influenza A os cientistas ainda discutiam se deveriam continuar fabricando a vacina contra as gripes sazonais ou partir para a produção em larga escala desta nova vacina, que 
provavelmente só estaria pronta no momento em que poderia haver um novo surto no hemisfério norte.

\section{Da Europa para o Novo Mundo}

A Gripe Suína é uma antiga conhecida. Segundo Roy Porter (2004), no seu "Das Tripas Coração, Uma Breve História da Medicina", "a primeira epidemia do Novo Mundo, que atingiu Hispaniola em 1493, bem pode ter sido a Influenza dos suínos, transportada pelos porcos que estavam a bordo dos navios de Colombo" (PORTER, 2004, p.27).

A epidemia de Influenza de 1918-19, ao devastar milhões pareceu ameaçar a própria civilização humana. Doenças como a sífilis, cólera e varíola têm devastado a humanidade por séculos. Um enorme acúmulo de evidências demonstra o papel central das pestilências nas relações humanas e na forma como transformaram o curso da história.

As pandemias causadas pelo vírus influenza A, são das mais graves que podem ocorrer, pois seu agente etiológico se divide em subtipos e pode contaminar tanto homens como animais. Essa peculiaridade Ihe permite sofrer mutações radicais e tornar-se um completo estranho para nosso organismo.

Homens e organismos infecciosos tem tido um longo e difícil relacionamento. A influenza foi capaz de reduzir grandes percentuais populacionais quando encontraram populações sem imunidade. Entretanto, os constantes intercâmbios dos grandes aglomerados populacionais da Eurásia permitiram a seus povos criar uma imunidade que os ameríndios não possuíam e que lhes foi fatal.

$\mathrm{Na}$ verdade não existia uma América desabitada para justificar uma colonização européia. As estimativas diferem bastante de autor para autor e merecem maior estudo dos cientistas e demógrafos, mas o Novo Mundo certamente não era desabitado. Parece que pelo menos 20 milhões de habitantes ocupavam esse continente. Aí entra uma importante chave do estudo de Diamond (2001). Por que, com uma população tão densa, não conseguiram os ameríndios a capacidade de criar imunidades aos patógenos do invasor. Por que a cada investida estrangeira, seja nos Andes, Mesoamérica ou no Vale do Mississipi sobrevinha uma mortandade sem par? A explicação do autor reside na falta de interligação comercial entre esses contingentes populacionais.

Segundo McNeill, a expansão européia é um fato tão sedimentado na história que por vezes esquecemo-nos das condições que possibilitaram esse desenvolvimento. 0 
continente pode capitalizar a nova capacidade demográfica com as supostas terras vazias de ameríndios, complementadas por Ilhas do Pacífico e Australianas, como também a Sibéria e as terras dos Khoekhoe ${ }^{6}$. Em todas essas regiões os europeus estavam na posição de controle dos transportes transoceânicos, além de outros meios de transporte e tecnologia superior àquelas populações dizimadas por doenças (MCNEILL, 1998, p. 212-234).

Nem o mais pessimista faria na época uma previsão de que a gripe pelo H1N1 de 2009 tivesse impacto decisivo em eventos históricos como os atribuídos por McNeill (1998, p.235 e 236) ao desenvolvimento populacional chinês ${ }^{7}$, à queda do Império Romano, a origem do Renascimento, a conquista da América ou a Revolução Industrial. Entretanto, uma das condições para que esses eventos tenham ocorrido, segundo esse autor, era a existência de grandes aglomerados populacionais, condição facilmente encontrada nessa crise e que encontrou fartura na capital mexicana.

Parece razoável supor que a criação de animais que antes vagavam livres e passaram a ser domesticados e confinados pela ação humana, fez com que se tornassem hospedeiros e responsáveis pela propagação de agentes infecciosos. Essa inter-relação criada entre humanos e animais nos últimos dez milênios torna-se, de certa forma, antinatural diante dos duzentos mil anos do homo sapiens. A quantidade de alimento gerada pela agricultura e por esses animais num pequeno espaço foi o que permitiu alimentar mais pessoas e colonizar novas terras e consequentemente propagar as doenças.

Nesse quadro, a transmissão dos agentes infecciosos tornou-se cíclica ou autossustentável. Aliada a densidade populacional, cada vez mais crescente e interligando a Eurásia por rotas de comércio, fez com que os patógenos assassinos pudessem se beneficiar dessa massa crítica populacional para se espalhar. Ao conquistarem os novos mundos, seja a América ou a Oceania, as vítimas foram os nativos, pois não havia entre esses povos,

\footnotetext{
${ }^{6}$ Khoekhoe, ou Khoikhoi (homens dos homens), anteriormente chamado hotentotes (pejorativo), como eram conhecidos os membros de um povo do sul da África que os primeiros exploradores europeus encontraram em áreas do interior e que agora geralmente vivem em assentamentos ou em reservas oficiais na África do Sul ou Namíbia . Retirado de: http://www.britannica.com/topic/Khoekhoe. Acesso em 12 de julho de 2015.

${ }^{7}$ McNeill ao estudar a China, ressalta que a única nova doença que havia lá chegado era a sífilis. Os padrões de contaminação por outras doenças devem ter sido similares aos europeus. Os registros de doenças a partir de 1300 são muito fragmentários, mas dobram no século XVII (pág. 235 e 236), provavelmente correspondendo ao real incremento das epidemias chegadas à China. Como esta vivia um momento político estável, é provável que os novos contatos chegados das viagens transoceânicas européias, sejam a causa. Ele estabelece uma relação entre o aumento da população chinesa de 65 milhões em 1400 para 150 milhões em 1600 como correspondendo à queda no crescimento populacional da Europa ocidental no mesmo período. Invernos rigorosos e estações mais curtas, desfavoráveis para a agricultura, bem como instabilidade política, provavelmente tiveram papel em manter a população chinesa no mesmo patamar em 1700 (150 milhões). Mas somente uma homogeneização nos padrões de infecção ao redor do mundo pode explicar o sistemático crescimento após a parada antes e depois do século XVII.
} 
domesticação de animais em larga escala, ou seja, hospedeiros para os agentes infecciosos que Ihes possibilitasse alguma imunidade. Essa chave permanece então, absolutamente válida, pois a letalidade da gripe do século XXI não se mostrou similar à Gripe Espanhola. Pode ser que tenhamos adquirido alguma imunidade, por um lado por estarmos frequentemente em contato com animais e por outro pela circulação desses patógenos por todo o mundo, às vezes em algumas horas, ou até mesmo pelas vacinações contra as influenzas sazonais que na verdade também simulam a transmissibilidade dos patógenos.

Quando domesticamos os primeiros mamíferos há cerca de 10 mil anos, numerosos grupos de animais de grande porte passaram a viver lado a lado com seres humanos. Não era incomum, num passado recente, animais vivendo dentro das casas á noite ou em nas estações invernais. Mulheres das tribos de Papua-Nova Guiné chegavam a amamentar leitões e a prática de relações sexuais de humanos com animais não é tão incomum como Diamond (2001) faz supor em seu livro.

Não podemos esquecer também da manipulação e do contato com os fluidos corporais de outras criaturas. Aqui entra o leite, carne, esterco entre outros. Nesse caso, o confinamento dos animais passa a ter importância maior, pois num espaço exíguo os patógenos têm maiores oportunidades de disseminação.

O vírus da gripe suína parece ter a capacidade ou adaptação para saltar de pessoas para outras com uma facilidade bem maior do que ocorreu, por exemplo, com o H5N1(vírus da Gripe Aviária), que tinha essa propriedade limitada. O que ocorreu, supostamente, é que devem ter surgido mutações que permitiram a instalação e adaptação dos patógenos ao organismo humano. O que era apenas um processo incipiente na gripe aviária pareceu estar se tornando muito mais grave em 2009.

Os vírus da gripe atacam todos os anos e sofrem mutações, se não fosse isso, bastaria tomar a vacina uma única vez para ser imunizado por toda a vida. Como ele muda, todo ano se produz uma nova vacina. As pandemias ocorrem quando a mutação de um ano para o outro é radical. É quando surge um vírus tão diferente que ninguém tem defesas contra ele. Foi assim com a Gripe Espanhola de 1918, com a Gripe Asiática de 1957 e com a gripe de Hong Kong, de 1968. As três pandemias do século XX surgiram de mutações radicais. Todas começaram brandas. Assim como a Gripe Espanhola, a segunda onda da Gripe Asiática foi mais virulenta. Matou 4 milhões. Já a segunda onda da gripe de Hong Kong manteve-se branda. Só matou 1 milhão. Em 1997, geneticistas reconstituíram o vírus de 1918. Era o A(H1N1), semelhante ao da gripe suína. Nas pandemias de 1957 e 1968, o vírus era de outro tipo. (MOON, 2009). 
A nosso favor tivemos o fato de que o nosso sistema imunológico já tinha enfrentado vírus similares o que provocou uma letalidade compatível aos vírus das influenzas sazonais, diferentemente do que ocorreu com os povos isolados e que foram quase ou totalmente extintos.

Entretanto, as similaridades com a Gripe Espanhola assustaram. Até mesmo na prevenção, comportamentos e ações se repetiriam (fig. 3 a 6).

Figura 3: Condutor de bonde em Seattle (EUA) utilizando máscara e controlando o acesso de passageiros sem elas.1918.

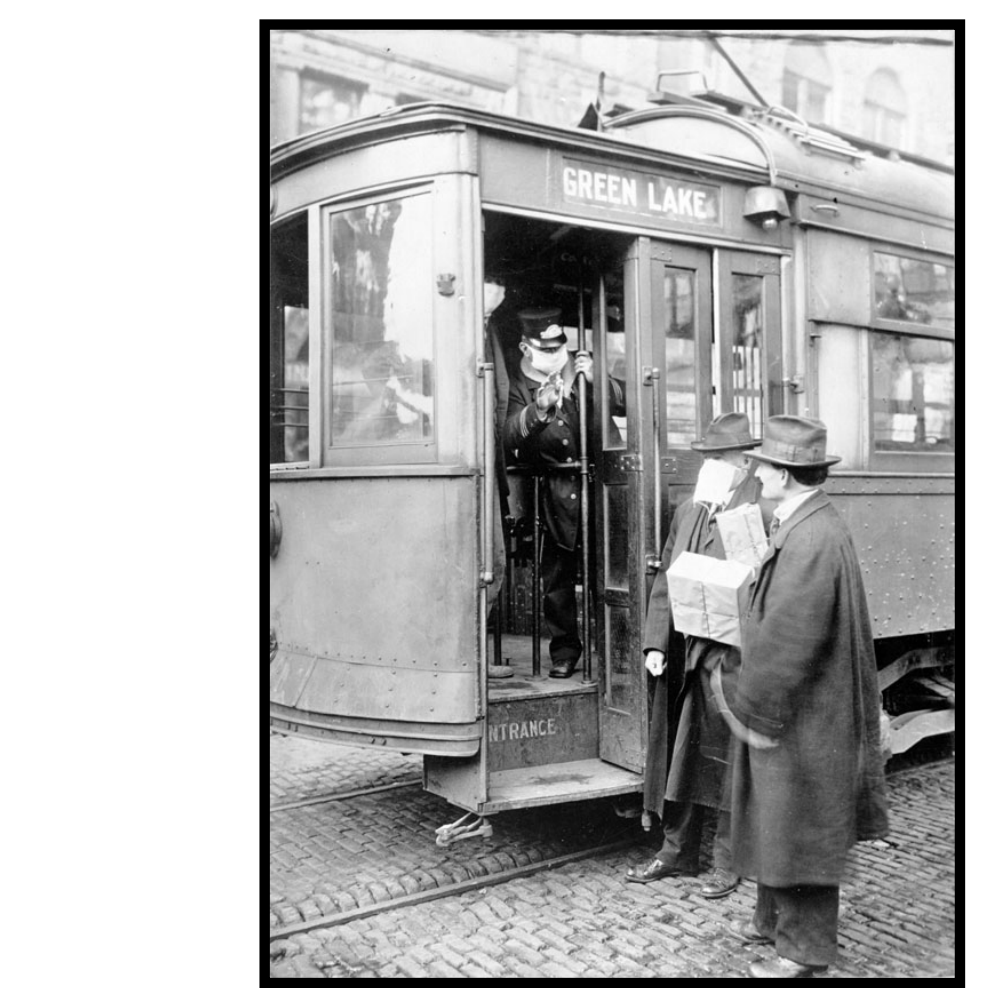

Retirado de: http://www.archives.gov/exhibits/influenza-epidemic/records-list.html.

Acesso em 19 de julho de 2015.

Figura 4: O Governo da Nova Gales do Sul na Austrália alertando sua população que "um perigo maior do que a guerra está ameaçando a vida de todos" e orientando que todos devam usar a máscara. 


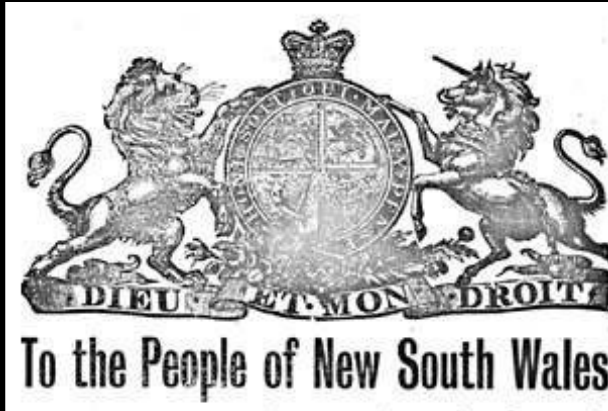

A danger greater than war faces the State of New South Wales and threatens the lives of all. Each day the progress of the battle is published in the Press. Watch out for it. Follow the advice given and the fight can be won.

Already the efforts made by the Government have had the effect of keeping the New South Wales figures down. But everybody is not yet working, so from TO-DAY on the Government insists that the many shall not be placed in danger for the few and that

\section{EVERYONE SHALL WEAR A MASK}

Those who are not doing so are not showing their independence - they are only showing their indifference for the lives of others - for the lives of the women and the helpless little children who cannot help themselves.

Retirado de: Howard Phillips and David Killingray, eds., The Spanish Influenza Pandemic of 1918-19: New

Perspectives (New York: Routledge, 2003), p. 117.

Figura 5: Passageiros do metrô na Cidade do México com máscaras cirúrgicas em 2009.

\footnotetext{
${ }^{8}$ Ao povo de Nova Gales do Sul. Um perigo maior do que a guerra se apresenta ao Estado de Nova Gales do Sul e ameaça as vida de todos. A cada dia o progresso da batalha é pubicado na imprensa. Fiquem atentos. Sigam as orientações dadas para que a luta possa ser vencida. Os esforços feitos pelo Governo de Nova Gales do Sul já surtiram efeito em manter o país sob controle. Mas nem todos estão trabalhando. Então, a partir de hoje o governo adverte que a maioria não pode ser posta em risco em detrimento de uma minoria e que todos devem usar máscara. Todos que não o estiverem fazendo estão mostrando sua independência, estão apenas mostrando sua indiferença pelas vidas dos outros-pelas vidas das mulheres e das pequenas crianças desamparadasque não tem como se ajudar.
} 


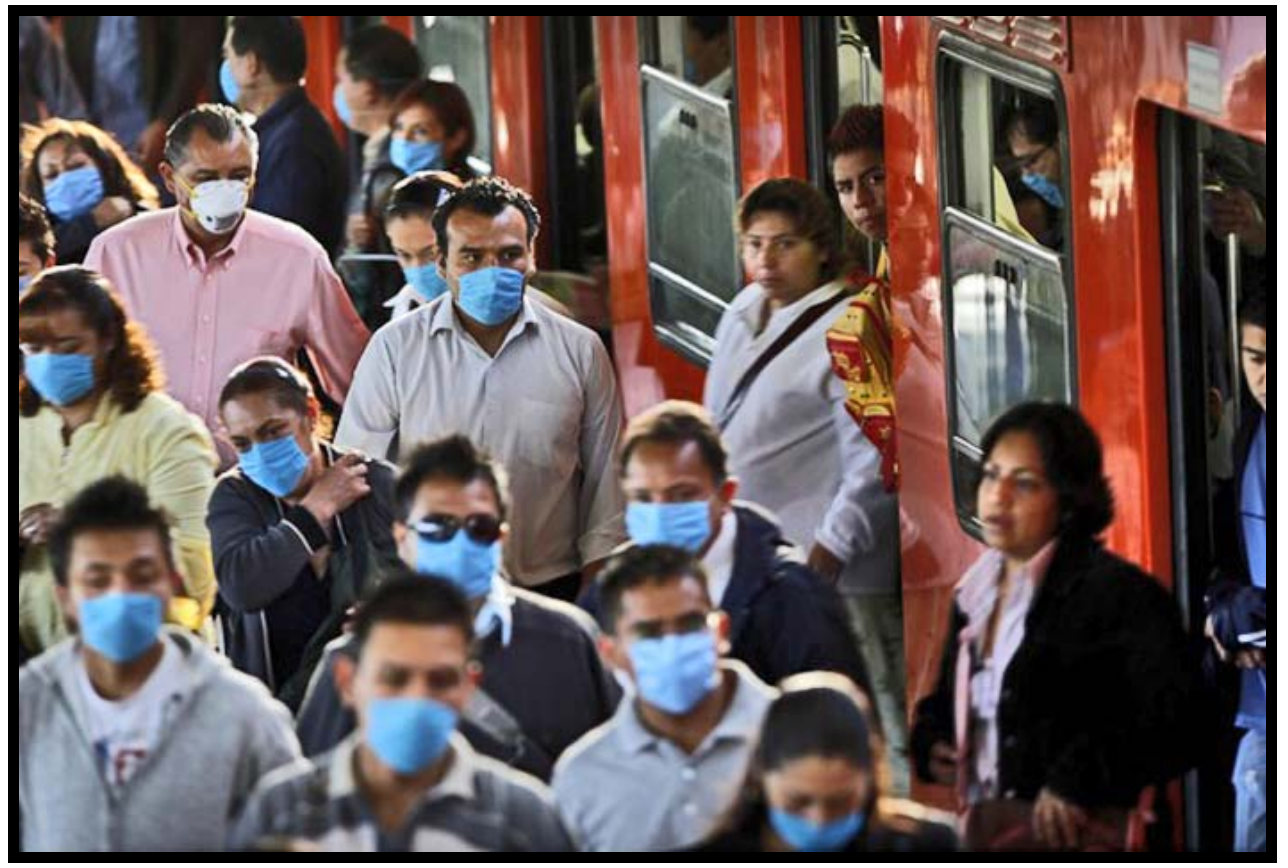

Retirado de: http://mexicocooks.typepad.com/mexico cooks/2009/05/. Acesso em 19 de maio de 2015.

Figura 6: Campanha para controle da gripe do Ministério da Saúde de Singapura em 2009.

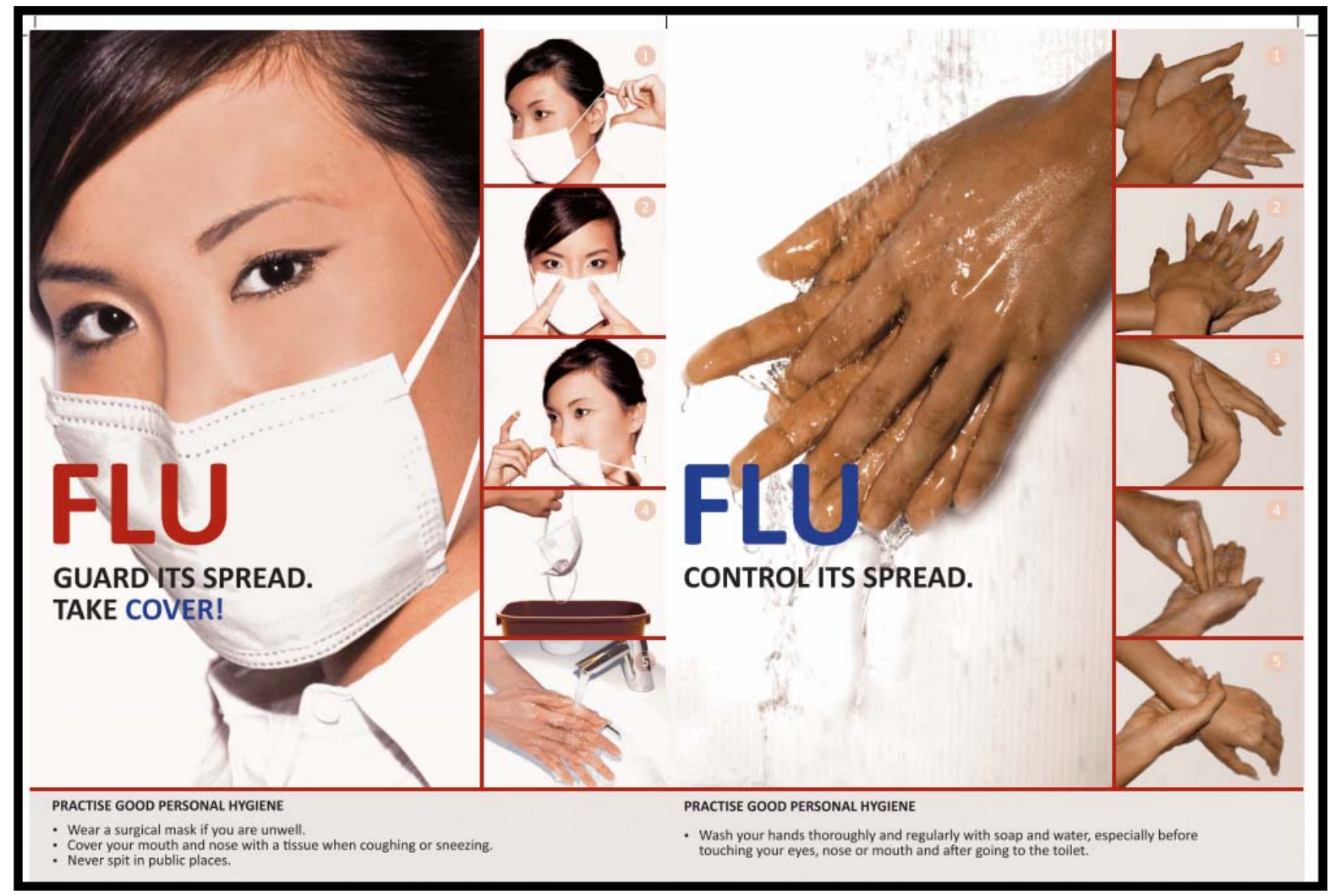

Retirado de : https://www.moh.gov.sg/content/dam/moh web/Diseases\%20and\%20Conditions/Resources/Posters/Handwashing\%202in-one\%20\%281\%29.pdf. Acesso em 20 de julho de 2015. 
Houve um primeiro surto (brando) de gripe na primavera de 1918 que ficou conhecida como "febre dos três dias", pois era a duração média dessa enfermidade. Como em 2009, a letalidade nesse período foi pequena, e passou quase despercebida ofuscada pela Guerra. Em setembro, com o vírus provavelmente mudado, o número de casos explodiu. Tendo ficado muito mais letal. A segunda onda que sobreveio foi uma das piores epidemias da história.

Nenhuma doença matou tanta gente em tão pouco tempo. Entre setembro e novembro de 1918 , a pandemia infectou até $20 \%$ da humanidade. Matou pelo menos 50 milhões de pessoas. Ninguém poderia imaginar que a "febre dos três dias" tinha sido a primeira onda da pandemia. Isso ficou claro quando se constatou que todos que a contraíram escaparam da segunda onda: haviam adquirido imunidade. (MOON, 2009).

No Brasil, a diferença de cuidado das autoridades públicas no trato das pandemias foi flagrante. Até que a imprensa nacional noticiasse os primeiros casos de gripe na cidade do Rio de Janeiro, no início de outubro de 1918, já havíamos recebido marinheiros brasileiros envolvidos na guerra, vitimados pela gripe no porto de Dakar e internados num hospital de Recife, local em que aportaram. Nessa ocasião, adotando um comportamento similar à eclosão do cólera, "as autoridades de saúde preferiram acreditar numa possível graça divina e não tomaram as medidas cabíveis para impedir que a doença aportasse em nossa terra" (TEIXEIRA, 1993).

\begin{abstract}
Nesse momento a cidade já havia se transformado num caos. Falta de alimentos, serviços públicos parados, saques, etc. Para completar este quadro alarmante surgia o problema dos cadáveres insepultos. Não havendo nos serviços municipais pessoal suficiente para recolher os mortos, a polícia passou a se encarregar deste expediente. Para proceder aos sepultamentos eram utilizados os presidiários da Casa de Detenção, e foi contratado pessoal extra, remunerado por dia de trabalho. Segundo os jornais, a política passou a seqüestrar desocupados, obrigando-os a enterrarem as vítimas da epidemia. Mesmo assim, o triste quadro de mortos amontoados pelos cemitérios ou abandonados pelas ruas desertas, era constante (TEIXEIRA, 1993).
\end{abstract}

Entretanto, apesar da calamidade no campo da saúde que se instalou no país, houve um ganho no que concerne às diversas abordagens como a "especialização da fala médica, os espaços privilegiados para aquela fala, a comunicação entre pares e com aqueles considerados leigos são questões que não surgiram com a epidemia de gripe espanhola", mas, devido à falta de relevância com que a gripe era tratada até então, promoveu o início 
"do processo de construção de uma forma de discurso específico entre doutores, com a paralela ordenação de informações pertinentes para os leigos", através de um cerco e proibição de comercialização de medicamentos, que anunciados há anos para um determinado fim, passavam a prometer um combate e prevenção eficaz da "espanhola". (BERTUCCI-MARTINS, 2005, p.144,145).

Em 1918, milhões sem imunidade morreram. Os esforços do pessoal de saúde pareciam em vão. A quantidade de doentes era desproporcional aos recursos para atendêlos.

Em 2009, apesar de milhares de doentes e mortes ocorridas pela pandemia do H1N1, as extensivas campanhas realizadas bem como a disponibilização de vacinas e antivirais, além de muito tempo e recursos investidos pelos orgãos de saúde pública em reposta ao virus deram uma face branda à pandemia em comparação à de 1918. Entretanto, a denominação "gripe suína", custou milhões aos cofres das indústrias dos países produtores de carne suína. Só nos EUA, a perda nesse campo, é estimada em 28 milhões de dólares por semana (TAYLOR E DACVPM, 2011, p. 79).

Apesar de todos os avanços científicos, principalmente na identificação do vírus- na época o microscópio eletrônico não havia sido inventado- e na decifração do seu DNA, o quadro foi, passados mais de 90 anos, similar à pandemia de 1918-19, no que concerne ao fato de que, segundo Souza (2005, p.72), a "[...] doença é um problema que tem uma dimensão biológica, mas também está carregado de conotações sociais, culturais, políticas e econômicas [...]", no artigo em que examina a Gripe Espanhola em Salvador.

Em 2009, esperava-se que por já ter sido sequenciado o DNA do vírus e pela existência de antivirais, tivessemos melhores meios de combater a epidemia, o que de fato ocorreu, entretanto, o total de doentes numa pandemia poderia crescer tanto e tão rapidamente, como de fato ocorreu entre abril e maio de 2009 (figura 7 e 8), que não havia e não há no planeta, médicos, remédios e leitos hospitalares em quantidade suficiente para cuidar de todos os casos graves. (Moon, 2009).

Figura 7: Linha do tempo dos casos confirmados de influenza $A(H 1 N 1)$ e mortes reportadas à OMS. Situação em 26 de abril de 2009, 2 países com 38 casos e 0 mortes. 


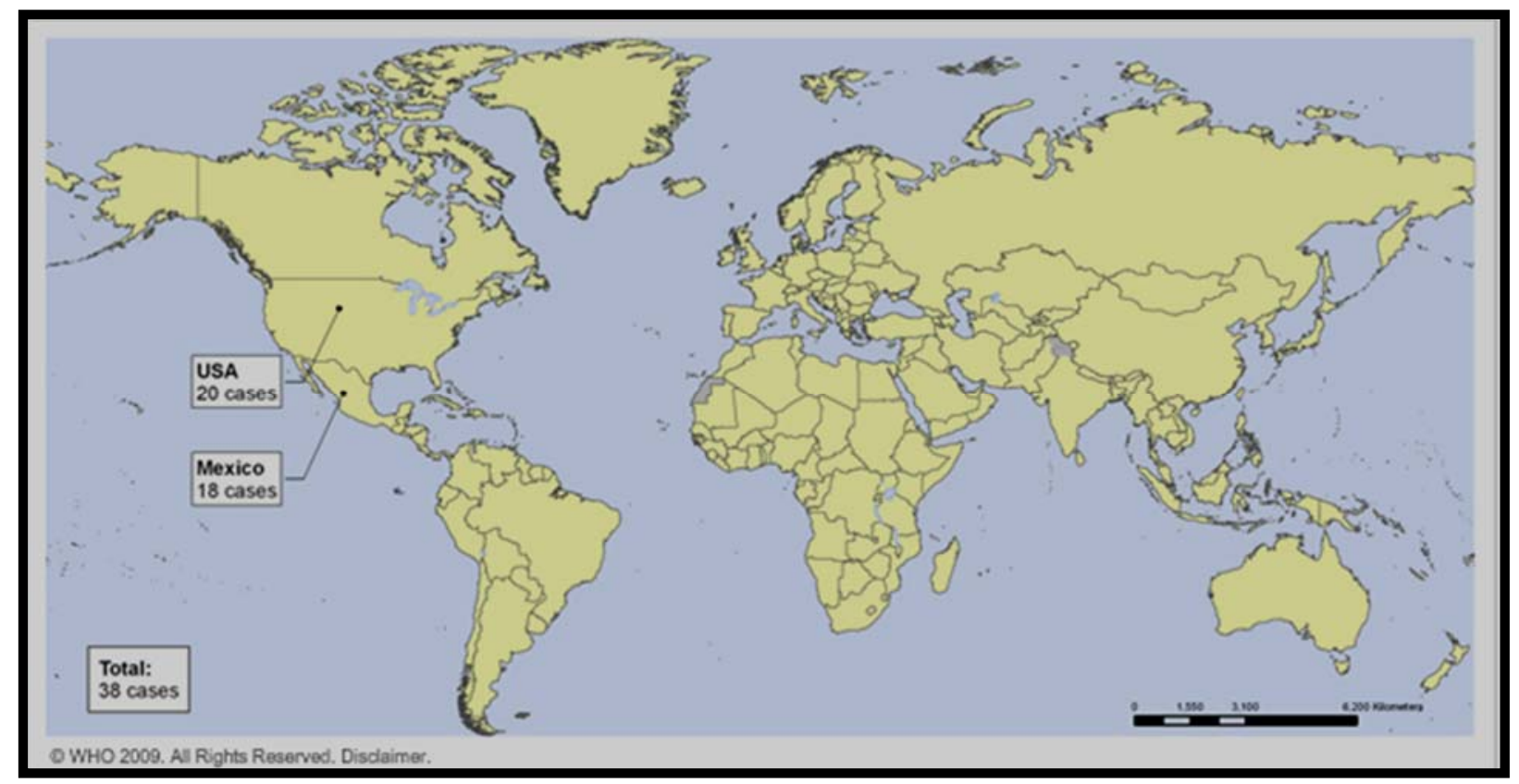

Fonte: OMS. http://www.who.int/csr/disease/swineflu/history map/InfluenzaAH1N1 maps.html. Acesso em 14 de julho de 2015.

Figura 8: Linha do tempo dos casos confirmados de influenza A (H1N1) e mortes reportadas à OMS. Situação em 12 de maio de 2009, 48 países com 13.398 casos e 95 mortes.

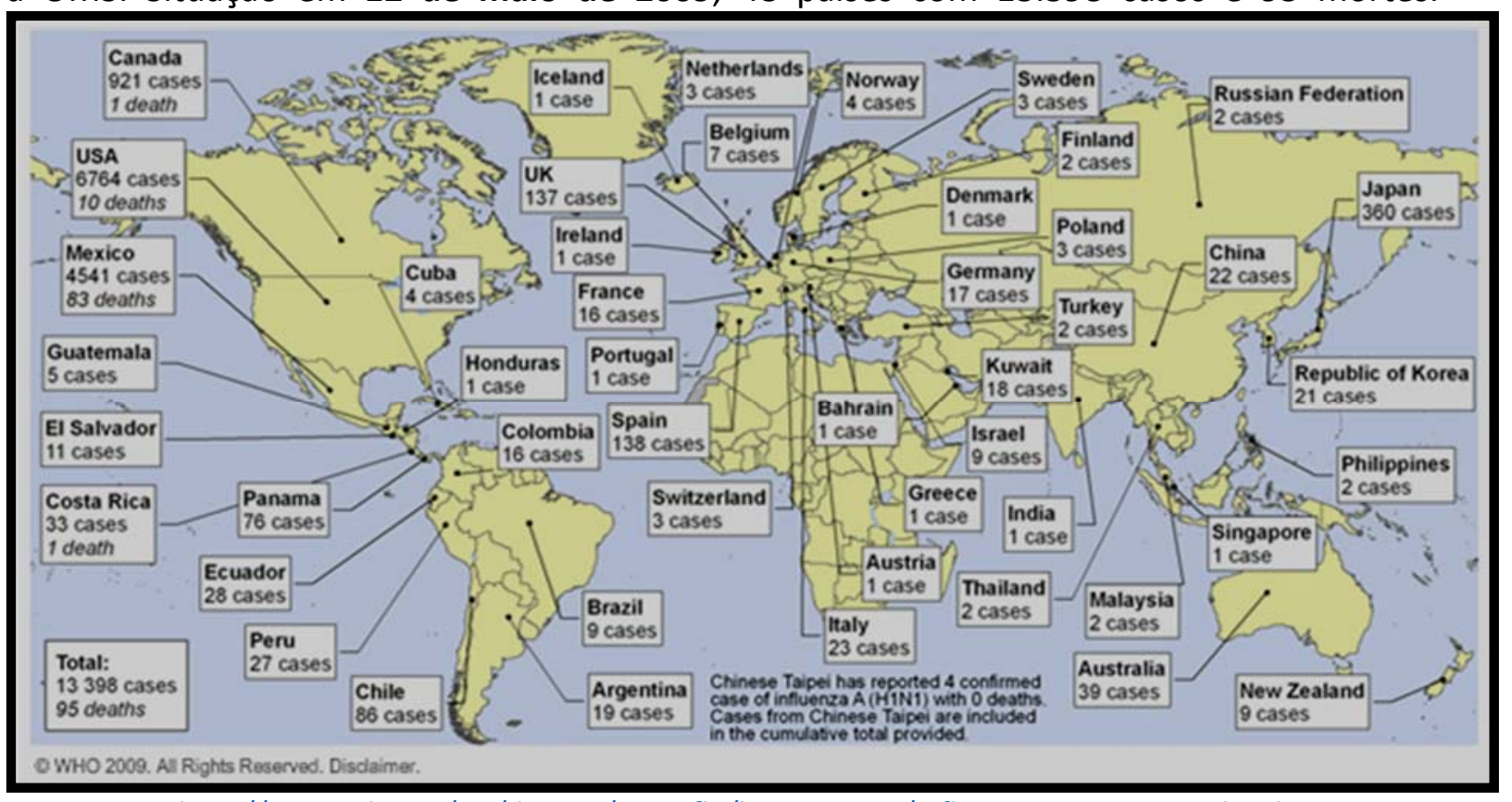

Fonte: OMS. http://www.who.int/csr/disease/swineflu/history map/InfluenzaAH1N1 maps.html. Acesso em 14 de julho de 2015. 
Entretanto, os recursos do Século XXI, deram um rumo diferenciado à pandemia. Para exemplificar com os Estados Unidos, o primeiro caso de H1N1, foi diagnosticado no dia 15 de abril de 2009. No dia 21 de abril, apenas 6 dias depois, os Centros de Controle e Prevenção de Doenças $(C D C)$ daquele país já estavam trabalhando no desenvolvimento de uma nova vacina. Apesar do esforço, a 26 de abril daquele ano, o governo americano decretou o vírus como uma emergência para a saúde pública. Em junho, mais de 18 mil casos já haviam sido reportados nos EUA. Em novembro do mesmo ano, quando 48 estados americanos reportaram a doença, mais de 61 milhões de doses de vacina estavam disponíveis. Nesse momento começou a ocorrer um declínio no número de notificações o que permitiu que fosse aplicada a vacina em mais de 80 milhões de pessoas. Os $\mathrm{CDC}^{9}$ americanos estimaram entre 43 e 89 milhões de pessoas tiveram o H1N1 entre abril de 2009 e abril de 2010 (U.S. DEPARTMENT OF HEALTH \& HUMAN SERVICES, 2015).

\section{Considerações Finais}

Estima-se que mais de 74 países foram afetados pela pandemia, com cerca de 18.500 mortos em todo o mundo desde que foi anunciada em abril de 2009. Num pronunciamento da Diretora Geral da OMS, Margaret Chan, em 10 de agosto de 2010, foi declarado que de acordo com os relatórios de vários países, apesar do H1N1 ainda ter continuado a circular, tenha passado a atuar mais com o comportamento de vírus de gripe sazonal, deixando de ser dominante em relação aos outros vírus de influenza, desta forma, tendo sido possível decretar o fim do alerta para a pandemia. Para que no período pós-pandemia eventos de magnitudes díspares não levassem ao recrudescimento da propagação dessa doença, ações enérgicas em termos de vigilância, rápida detecção e tratamento e vacinação recomendada, forneceram o modelo de como outros países poderiam precisar responder frente a focos localizados de diferentes proporções (CHAN, 2010).

O surgimento de pandemias é de difícil predição e são muitas vezes, capazes de promover surpresas. A pandemia do século XXI vitimou menos em comparação à de $1918 \mathrm{e}$ principalmente quanto ao temor por ocasião de seu surgimento em abril de 2009. Alguns fatores como a não mutação do vírus em uma forma mais letal, a vacinação e a atuação global dos países, mesmo os que apresentam um sistema de saúde pública ainda incipiente, contribuiram para essa realidade. Sem essa combinação de fatores, provavelmente teríamos uma diferente realidade nos dias de hoje.

\footnotetext{
${ }^{9}$ CDC: Center for Disease Control and Prevention (Centro de Controle e Prevenção de Doenças).
} 
Pandemias de gripe se assemelham a grandes catástrofes naturais: sabemos que haverá uma outra, mas ignoramos quando e qual será a sua magnitude. Na maioria dos outros aspectos, elas são diferentes. Terremotos em Tóquio ou San Francisco tem a duração de segundos a minutos - pandemias se propagam ao redor do mundo em ondas sucessivas por meses ou por um par de anos. E as consequências são bastante diferentes: uma pandemia de gripe pode ser mil vezes mais mortal do que o mais mortal tsunami (KAMPS E REYES-TERÁN, 2006, p.17).

Novos padrões na produção de alimentos, comércio e viagens criaram oportunidades para antigos e novos patógenos. Apesar de existir consenso em algumas medidas que devam ser tomadas preventivamente pelas autoridades sanitárias em todo o mundo, tais como, aprender as lições do passado estudando pandemias e outras ameaças à sáude pública, a necessidade de haver uma preparação global e conjunta para as novas pandemias de influenza que surgirão, incremento nas medidas de preparação e prevenção locais, estabelecimento de estratégias para prevenção e controle da transmissão da doença entre animais e homens, formalização das questões jurídicas na prevenção e controle, preparação para a melhoria da vigilância, aumento na capacidade científica de predição, rapidez no compartilhamento da informação entre os países e no manejo da crise a eficácia de manter a credibilidade preservada (KNOBLER et al, 2005,p. xii, 66), a população humana continuará a enfrentar os desafios no ressurgimento de antigas doenças e de novos organismos infectantes.

REFERÊNCIAS BIBLIOGRAFICA

BERTUCCI-MARTINS, Liane Maria. Entre doutores e para os leigos: fragmentos do discurso médico na influenza de 1918. História, Ciências, Saúde - Manguinhos, v. 12, n.1, p. 143-57, jan. - abr. -2005.

BRIDGES, Buxton Carolyn et al. Risk of Influenza A (H5N1) Infection among Poultry Workers, Hong Kong, 1997-1998. The Journal of infectious diseases, p. 10015-1010, 2002.

BRYAN, Jenny. Vaccination. It may not be perfect, but the influenza vaccine has saved many people's lives. The Pharmaceutical Journal, 15 MAY 2014. Retirado de http://www.pharmaceutical-journal.com/sign-in?rtn=in-depth/perspective-article/it-maynot-be-perfect-but-the-influenza-vaccine-has-saved-many-peoples-lives/11138389.article. Acesso em 13 de julho de 2015. 
CHAN, Margaret. Pronunciamento de abertura de conferência virtual com a imprensa. Site da Organização Mundial de Saúde. 10 de agosto de 2010. Retirado de: http://www.who.int/mediacentre/news/statements/2010/h1n1_vpc 20100810/en/.

Acesso em 15 de julho de 2015.

. Opening Remarks at the New Delhi International Ministerial Conference on Avian and Pandemic Influenza. 4 de dezembro de 2007. Retirado de: http://www.who.int/dg/speeches/2007/20071204 new delhi/en/. Acesso em 23 de julho de 2015.

CHENG, Vincent. C.C.et al. Clin. Microbiol. Rev. 25 no. 2 223-2631, abril 2012.

CROSBY, Alfred W. Germs, Seeds and Animals: Studies in Ecological History. M.E..Sharpe. 232 p.1994.

Doenças, p. 175-192 In: Imperialismo Ecológico: a expansão biológica na Europa 900-1900. São Paulo: Companhia das Letras, 1993.

. Epidemic and Peace: 1918. Greenwood Press, Westport,

Connecticut, 1976.

DEHNER, George. Flu: Past and Present History Compass 5/2 , p. 709-724, 2007.

DIAMOND, Jared. "O presente letal dos animais domésticos: a evolução dos germes". In: Armas, germes e aço: os destinos das sociedades humanas. Rio de Janeiro/São Paulo: Record, p. 195-214, 2001.

HERRING, D. Ann, LOCKERBIE, Stacy. "Ten: The Coming Plague of Avian Influenza," in Plagues and Epidemics: Infected Spaces Past and Present, ed. D. Ann Herring and Alan C. Swedlund, p. 180, New York: Berg, 2010.

KAMPS, Bernd Sebastian e REYES-TERÁN, Gustavo. Influenza 2006 in Influenza Report 2006. Editado por Kamps et al, Flying Publisher - Paris, Cagliari, Wuppertal, Sevilla, p. 17, 2006.

KILBOURNE, Edwin D. Influenza Pandemics of the 20th Century. Emerging Infectious Diseases, Vol. 12, No. 1, January 2006.

KNOBLER, Stacey L., et al. The Threat of Pandemic Influenza: Are We Ready? Workshop Summary. Disponível em: http://www.ncbi.nlm.nih.gov/books/NBK22156/pdf/Bookshelf_NBK22156.pdf. Acesso em 12 de maio de 2015. 
KOLATA, Gina. Gripe: a história da pandemia de 1918. Rio de Janeiro, Record, 2002.

MCNEILL, Willian H. Transoceanic disease exchanges: 1500-1700. In: MCNEILL, Willian Plagues and peoples. New York: Anchor Books, p. 208-241, 1998.

MOON, Peter. Alfred Crosby- "Avacina poderá chegartarde demais". Revista Época online: Disponível em: http://revistaepoca.globo.com/Revista/Epoca/0,EMI76971-15257,00ALFRED+CROSBY+A+VACINA+PODERA+CHEGAR+TARDE+DEMAIS.html . Acesso em 09 de junho de 2015.

NEUMANN, Gabriele; NODA, Takeshi; KAWAOKA, Yoshihiro. Emergence and pandemic potential of swine-origin H1N1 influenza virus. Nature 459, 931-939 (18 June 2009).

OLSON, Trisha. Prepare for the H5n1 Flu Pandemic, Law \& Order, maio, 2006.

PHILPOTT, Tom. Swine-flu outbreak could be linked to Smithfield factory farms. Disponível em: http://www.globalresearch.ca/swine-flu-outbreak-could-be-linked-tosmithfield-factory-farms/13413. Acesso em 15 de maio de 2015.

PHILLIPS, Howard e KILLINGRAY, David, editors. The Spanish Influenza Pandemic of 1918-19: New Perspectives, New York: Routledge, p. 117, 2003.

PORTER, Roy. Das Tripas Coração, Uma Breve História da Medicina, 2004.

RAZURI, Hugo; ROMERO, Candice et al., "Population-Based Active Surveillance Cohort Studies for Influenza: Lessons from Peru, "Bulletin of the World Health Organization 90, no. 4 (2012).

SOUZA, Christiane Maria Cruz de. A gripe espanhola em Salvador, 1918: cidade de becos e cortiços. História, Ciências, Saúde - Manguinhos, v. 12, n. 1, p. 71-99, jan.-abr., 2005.

TAYLOR, Tegwin K.; DACVPM, DVM, MPH. "Chapter 5- Emerging Diseases," in Animals, Diseases, and Human Health: Shaping Our Lives Now and in the Future, Radford G. Davis, Santa Barbara, CA: Praeger, 2011.

TEIXEIRA, Luiz Antônio. Medo e morte: sobre a epidemia de gripe espanhola de 1918, Série Estudos em Saúde Coletiva, Rio de Janeiro, UERJ, no 59, out. 1993.

TRILLA, Antoni, Trilla, Guillem; DAER, Carolyn. The 1918 "Spanish Flu" in Spain. Clinical Infectious Diseases (2008) 47 (5): 668-673 doi: 10.1086/590567.

U.S. DEPARTMENT OF HEALTH \& HUMAN SERVICES. Pandemic Flu History, 2015. Retirado de http://www.flu.gov/pandemic/history. Acesso em 26 de julho de 2015. 
WEBSTER, Robert G.; KAWAOKA, Yoshihiro. Influenza-an emerging and re-emerging disease. Virology, Vol 5, p 103-111, 1994.

WORLD HEALTH ORGANIZATION. China's latest SARS outbreak has been contained, but biosafety concerns remain - Update. 18 de maio de 2004. Retirado de: http://www.who.int/csr/don/2004 05 18a/en/. Acesso em 21 de maio de 2015.

WORSTER, Donald. Transformações da Terra: Para Uma Perspectiva. Agroecológica Na História. Ambiente \& Sociedade - Vol. V - n o 2 - ago./dez. 2002 - Vol. VI - n o 1 - jan./jul. 2003. 